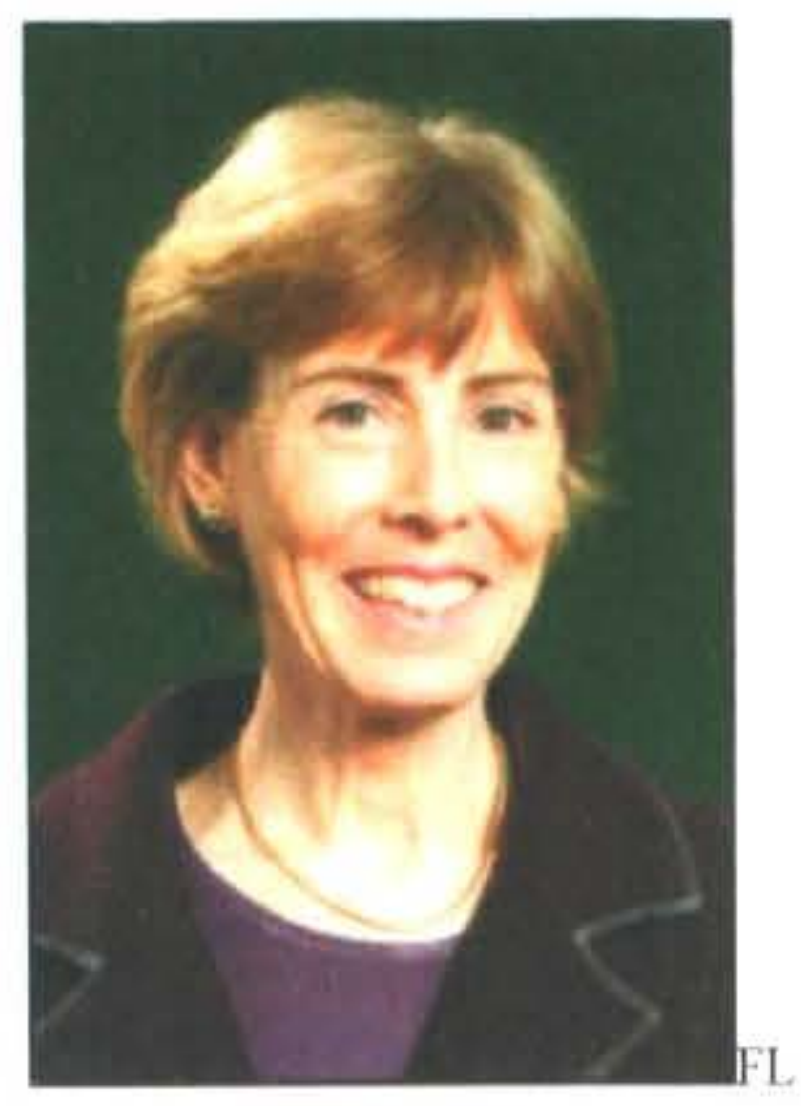

\title{
OCCUPATIONAL HEALTH AND \\ SAFETY IN THE KUWAIT \\ CONSTRUCTION INDUSTRY: \\ THE RATIONALE FOR \\ RESEARCH
}

\section{Cathy Robertson and Felicity Lamm}

\author{
Department of Occupational Health and Safety \\ and School of Business \\ Auckland University of Technology
}

\begin{abstract}
Over half of all construction businesses in Kuwait are small firms employing fewer than 10 employees, most of whom are contingent, migrant workers. There is also anecdotal evidence that the practice of employing illegal migrant labour in the Kuwaiti construction industry, particularly amongst sub-contracting firms, is rife. There is disturbing indications that the injury and illness rate amongst construction workers is extremely high. The paper will present the rationale for the proposed study and highlight the characteristics of the Kuwaiti construction industry. A brief review of the literature outlined in the paper will also attempt resolve (or not) the following questions: what are the intersections between the literature on contingent workers and the literature on OHS in the construction industry? In addition, what does the research literature say on the extent to which cultural factors shape employers ' practices and attitudes toward employment relations and workplace health and safety? Finally, areas for future research on the topic will be identified and mapped out.
\end{abstract}

\section{Introduction}

During the first half of he 20th Century, labour historians saw connections between worker organisation and laws pertaining to minimum wages/maximum hours (Quinlan 1997). Workplaces have changed significantly over the past 20 years. According to Quinlan and Mayhew (2001) there has been a significant growth in those working under sub-contracted, franchised, selfemployed or part-time arrangements, falling into socalled "contingent" or "precariously employed" work groups. There is growing empirical evidence that the growth of contingent and precariously employed workers is negatively related to injury and illness, reporting propensity, treatment and rehabilitation (Valcarel 2004; Xia. Lu and Liang 2004: Nossar, Johnstone and Quinlan 2004; Kartam and Bouz 1998). The ILO estimates that at least 60,000 fatalities occur at construction sites around the world, every year. There is growing evidence that contingent workers in the construction industry contribute significantly to this figure. Contingent workers in many countries face working conditions which resemble those of industrialised countries 100 years ago, when unsafe working conditions, unfair wages and long working hours gave rise to labour movements. The situation in today's economic environment, where large numbers of contingent workers are employed on construction sites, has not significantly changed. The focus of this study is on construction workers in Kuwait, where workers face the same difficulties pertaining to lack of communication and agreement on OHS compliance legislation, resulting in minimal or lack of enforcement. (Kartam and Bouz 1998; Kartam, Flood and Koushki 2000; Kazemi and Ali 2002, Valcarel 2004).

The rights of contingent workers in Kuwait, and in particular, their health and safety have become a catalyst for the call for employment reforms in Kuwait and is an area which is currently being targeted by human rights groups and the International Labour Organisation (The ILO). In 2003 the organisation Human Rights Watch, in a letter to his Highness Sheikh Jaber al-Ahmad al-Jaber Al Sabah, the now deceased Amir of Kuwait, recommended that the state of Kuwait take steps to ratify the International Convention on the Protection of the Rights of all migrant workers and members of their families. The ILO and the Kuwait authorities have had an on-going relationship since the 1980's. Kuwait has responded positively to the need for the institutionalisation of health and safety regulations and Kuwait has now ratified a total of 19 ILO Conventions. The Health and Safety requirements in the Oil Sector are most stringent and great care is taken to ensure that Project Management Consultants (PMCs) assume responsibility and accountability for ensuring that the workplace is safe for Contractors. The breakdown in the chain of command and control occurs when Contractors sub-contract and the sub-contractors re-subcontract. This research will analyse the effect of this process on the health and safety of contingent workers. 
The priority given to the "Kuwaitisation" of the labour force, to the exclusion of foreign workers, is of great concern (ILO Regional Office 2001). The sociological and cultural origins gave rise to the particularly strong sense of national pride and feelings of superiority over other tribal groups and nationalities. These cultural traits became more evident after the Iraqi invasion of Kuwait in 1990.

The Gulf war produced a unique paradox in that the Iraqi invasion and occupation strengthened the sense of nationalism for Kuwaiti citizens. The cultural effects of having gained independence because of American intervention served to strengthen the rift between espoused and practiced Kuwaiti values and ethics. Publicly and outwardly, Kuwait supported and still supports the United States government, however inwardly Kuwaitis resent being dependent on a Western culture and seek to subjugate Westerners through the managerial culture dominated by autocratic tribalistic values. This has resulted in a tension caused by the juxtapositioning of Western and Kuwaiti cultures within Kuwait, exacerbated by external pressures by ILO and Human Rights agencies. This duality is one of the most serious stumbling blocks in efforts at nation-building, where most governmental exertions serve to "protect" Kuwaitis against the alien migrant population and against three powerful neighbours - Iraq, Iran and Saudi Arabia, who have traditionally attempted to control events in Kuwait. Thus Kuwait needs the powerful presence of International forces to maintain its independence from threatening neighbours whilst struggling to dominate and rule expatriate workers by official stratification of the workforce. At the same time Kuwaitis seek to reduce the possibility of being dominated by expatriate values through imposing authoritarian and dictatorial traditional management practices. (Loew 2007; Human Rights Alert series 2008).

This polarisation of the workforce is exacerbated by the fact that nationals, through the entrenched belief in their cultural superiority, have seen no need to gain technical competence, work values and career orientation and prefer to rely on imported human capital to manage technological operations. (Abdul-Hadim 1989, Kazemi and Ali 2001; Human Rights Alert series 2008).

These factors have given rise to the official stratification in labour and the development of managerial problems such as primacy of personal relationships over work relationships, favouritism and personal loyalty at work, unwillingness to shoulder responsibilities, multiplicity of rules and regulations, rigid and obsolete administrative systems and policies, and influence of cliques in the workplace.

These tendencies are sanctioned by the Kuwaiti government and are institutionalised through government legislation and decrees supporting authoritarian tribal attitudes. Loyalty is considered above ability and the patriarchal family is the strongest state institution. Government allocates resources based on group and tribal considerations and the fear of powerful neighbouring countries. These factors further strengthen conformity to traditional customs. (Kazemi and Ali 2001; Longva 1993; Loew 2008; Al-Otaibi 1991; Metle 2002).

A paradox therefore exists in that although non-Kuwaitis and expatriates are considered to be at a lower social level than the Kuwaitis and are subject to discriminatory work practices which discourage individual initiative and encouraging conformity and subjugation, expatriates and non-Kuwaitis are nevertheless held responsible for ensuring high standards of Western work ethics. In addition, non-Kuwaiti PMCs (Project Management Consultants, are held responsible for satisfying international pressures by ILO and OHS agencies to improve working conditions and ensure that employees adhere to health and safety standards. At the same time, the Kuwaiti owned businesses minimise costs wherever possible. This complete focus on profits impacts negatively on health and safety, training, availability of suitable safety equipment and ultimately the welfare of contingent and precariously employed workers.

Kuwaitis go to great lengths to promote a positive public image through elaborate etiquette, ceremony and media exposure of Kuwaitis only, to publicly claim that international concerns pertaining to management practice and health and safety are being met, whilst at the same time holding expatriates and non-Kuwaitis accountable for ensuring that these concerns are being met. (Kazemi and Ali 2001; Tabtabai 2002).

Empirical studies thus show that managerial and sociocultural problems in Kuwait have a major impact on accident statistics. Statistics show that the majority of workers involved in workplace accidents were from the contingent and precariously employed sectors of the construction industry. In 1999, 98 accidents per month occurred in the construction industry. Table 1 shows the distribution of labourers on construction sites and their nationalities. (Tabtabai 2002)

It can be seen from the table below that most injured workers in Kuwait are expatriates from countries with their own languages and customs. With the exception of Iranians and Egyptians, most workers will not understand Arabic. This situation is exacerbated by the fact that the Arab dialect differs from region to region, making it difficult even for Arabic speakers to follow the local Arabic dialect (Longva 2998; Metle 2002). All ethnic groups, who are largely uneducated and functionally illiterate, cannot understand or communicate in English. (Kartam and Bouz 1998). 
Table 1: Kuwaiti Injured Workers by percentage and nationality (1999)

\begin{tabular}{|l|l|}
\hline Nationality & $\%$ \\
\hline Egyptians & 58.4 \\
\hline Indians & 10.4 \\
\hline Syrians & 7.1 \\
\hline Pakistanis & 5.2 \\
\hline Iranians & 2.6 \\
\hline Bangladeshi & 3.2 \\
\hline
\end{tabular}

Adapted from Tabtabai, H. (2002)

These factors contribute significantly to the inability to educate and train contingent labour, particularly in the Kuwait construction industry. The problem is compounded by the transitory nature and relatively short duration of projects. (Valcarel, A (2004; Xia et al 2004).

\section{Literature Review}

The OHS literature will be analysed to determine areas of global accident causation factors which intersect with accident causation factors in Kuwait. This will provide the platform from which cultural factors shaping employer practices and attitudes affecting worker health and safety in Kuwait may be contextualised within empirical literature on the prevailing health and safety climate for precariously employed workers.

\section{Accident Causation Factors}

\section{Competitive Tendering}

Quinlan and Mayhew (2001) claim that since the 1970's and fuelled by the growth of neo-liberal ideas advocating self-regulation, privatisation, globalisation, free trade and enhanced competition. The result has been an increasing tendency by industrialised countries to advocate competitive tendering and outsourcing of labor in order to free up the labour market. The result has been a growth in precarious employment correlating positively to the increase in non-reported work-related injury and illness.

Increase in the number of smaller and selfemployed contractors and sub-contractors.

McVittie, Banikin and Brocklebank (1997) in a review of accident rates of transportation for trucking firms in the United States in 1994, revealed that the smallest forms had the highest frequency with a noticeable decrease as the firm sie increased. Sust (1971), shows that as firm size decreases, injury increases. Owner-operated companies represent $8 \%$ of the total workforce in the US and account for $19-20 \%$ of all fatal injuries, with the disparity being even more evident in the construction industry. (Quinlan and Mayhew 2001; Weeks and
McVittie 1995, Toscano and Window 1994). In the UK, agriculture and construction employed $30 \%$ of selfemployed workers, accounting for over $70 \%$ of all work related fatalities (Quinlan Mayhew 2001, Standing and Nicolini 1997). In the EU, over $50 \%$ of all self-employed workers were found to have problems from the pace of work, including increased psychological risks (Goudswaard et al 1999; Quinlan and Mayhew 2001; Letourneux 1991).

For small businesses, there is a tendency towards fatalistic resignation to OHS risks being an unavoidable part of the job. This has lead to an emphasis on the individual as opposed to technological controls for OHS risk. The implications for small businesses are that workers' perceptions present significant barriers to implementation of OHS management strategies, particularly in accidents involving height access equipment. (Lingard and Holmes 2001)

Table 2: Building Construction Industry Workforce Size vs Accident Rates (June 30 1999)

\begin{tabular}{|l|c|}
\hline \multicolumn{2}{|c|}{ Accident Ratio Statistics } \\
\hline Technicians & 4,230 \\
\hline Tradesmen (Skilled Labour) & 38,399 \\
\hline Unskilled Labour & 64,834 \\
\hline Total & 104,463 \\
\hline Percentage to total workforce & $14 \%$ \\
\hline Number of accidents & 1,182 \\
\hline Percentage to total accidents & $35.9 \%$ \\
\hline Accident Ratio (per 1000) & 11.0 \\
\hline
\end{tabular}

Adapted from Tabtabai (2002)

\section{Lack of accurate and relevant data}

Statistical data on the number of fatal occupational accidents in construction is a global problem, as information on this topic is not available for most countries and few reports exist which describe the effects of firm size on occupational injury rates (Vacalrel 2004; Dainty et al 2001). Statistics in Kuwait are incomplete and inaccurate as many accidents are not reported to the Kuwait Municipality, the official reporting body for all industries (Kartam and Bouz 1998). Therefore the exact number of accidents in Kuwait is unknown.

The reasons for the lack of reporting in small businesses are (a) Unawareness of legislation; (b) Project Managers hide negligence because of the possibility of increased costs of enforced corrective and preventative actions; (c) Individuals do not report injuries to protect their employability; (d) No established company policies for accident investigation and reporting; (e) Avoidance of blame on the part of site engineers in the interests of selfprotection ( $\mathrm{f}$ ) Worker ignorance due to lack of education, language and cultural barriers; (g) Loss of production 
time; (e) Worker perceptions that accidents are attributable to their own negligence.

\section{Lack of cohesive and co-ordinated approach to occupational health and safety administration.}

Valcarel (2004) claims that a universally specific approach to occupational safety and health in the construction industry is required as a result of the temporary nature of the workplace. This is particularly true of small construction firms where the growth of subcontracting has led to a host of problems which hinder access to shared occupational health and safety resources which would assist in communication, planning, administration, consistent procedures and enforcement measures. Restricted and hindered access to these policies are also attributable to the fact that subcontractors are at the lower end of the interorganisational hierarchy in a construction project which severely limits their ability to exert influence on policy and decision making in spite of their day-to-day exposure to OHS risks. (Dainty et al 2001; McVittie et al 1997; Quinlan and Mayhew 2001; Lingard and Holmes 2001; Valcarel 2004; Xia, Lu and Liang 2004;

In Kuwait, the complex legal structure surrounding accident reporting and workmen's compensation is managed by Kuwaiti governmental bodies who are culturally suspicious of all expatriate activities.. This discriminatory attitude is entrenched in law through the stratification of expatriates. This leads to under-reporting of accidents and significantly hinders the process of evaluation and improvement of systems and processes aimed at improving health and safety conditions on construction sites. (Kazemi and Ali 2001).

\section{Low priority of Safety}

The low priority which is awarded has led to many factors which have resulted in a dramatic increase of workplace accidents and reduction in reported accidents. Dainty et al (2001) in a study of the growth of subcontracting in the UK, stated that in spite of $57 \%$ of the gross work undertaken in construction projects, Subcontractors hold generally negative views of partnering and supply chain management, due to the lack of understanding on behalf of main contractors of partnering and strategic alliances which hinder the development of trust, support and benefit in the supply chain.

The literature attributes the low priority which safety issues are given, as follows: (a) Focus on high profit levels (b) Programming/time related issues because of tight project deadlines and unrealistic time-line programming (b) Non-provision of cost of health and safety measures as part of the tendering process (c) Poor literacy and education levels leading to high training costs. (d) Poor quality of information such as missing, late or inaccurate data; (e) Ambivalance towards subcontractors' needs for prompt and accurate design information, exacerbated by general reluctance to draw upon the expertise of specialist subcontract and supplier companies; (f) Poor attitudinal issues. Aggressiveness aimed at sub-contractors due to the adoption of autocratic and dictatorial management styles severely inhibit better project management integration.

Autocratic attitudinal issues are particularly relevant in Kuwait, where management is characterised by favoritism, subjectivity in evaluation and promotion (including choice of subcontractors) multiplicity of rules and regulations, inflexibility and adherence to traditional customs including institutionalised and legal stratification of the labour force. (Longva 2008; Metle 2002; Tabtabai 2002; Quinlan and Mayhew 2001; Valcaral 2004; Zhao et al 2004; Kartam et al 2000; Kartam and Bouz 1998; Lingard and Holmes 2002; Dainty et al 2001)

Attitudinal issues are further exacerbated by the propensity towards traditionalist views in Kuwait where the right of the owner is held reverend within local cultural norms. This attitude in turn leads to tensions between traditionalist and western view of management practice and policies within which the paradox is exacerbated by externally portrayed adherence to international norms such as ILO conventions which the Kuwaiti Government have ratified, and internally contradictory applied values in terms of their enforcement. (Shah et al 1991; Longva 2008; Metle 2002; Kazemi and Ali 2002).

It is clear from the above that it is essential to adopt a multi-dimensional research approach which allows for analysis and discussion of all the factors which contribute towards the high rate of accidents in the Kuwait construction industry and in particular those involving contingent and precarious workers.

\section{Research Approach and Methodology}

Quinlan (1988), in his critical assessment of psychological and sociological research argued that the dominance of industrial psychologists in conducting early occupational health and safety research has created a propensity to attribute accident causation to the individual person, who reacted to a given set of environmental factors in a manner determined by their own personal characteristics. Early studies of accident causation led to the growth of the study of ergonomics which is primarily concerned with the relationship of the worker with his or her physical working environment. No notion was developed which related social workplace relations to occupational illness. This emphasis on personal characteristics of the individual worker would appear to exclude the notion of management responsibility for causing the behaviour that gives rise to accidents. 
Quinlan (1988) further states that notions of "worker apathy, deviant or incorrect work practices and carelessness" pervade the accident prevention and safety literature (1988:191). Quinlan cites Hopkins and Palser (1984) who developed four categories of victim blaming, namely accident proneness, ignorance or carelessness, machismo and malingering. Accident proneness proposes that certain individuals are inherently more susceptable to injury at work. Quinlan observes that although the internal logic of this explanation had been severely questioned (Ferguson 1973, Bull 1981) claimed that enthusiasm of researchers to attempt to correlate accidents with personal characteristics had not been dampened. The theory became popular with employers, insurance companies and the medical profession.

Furthermore, accusations of accident proneness became associated with societal prejudice, leading to allegations that certain ethnic groups were prone to illnesses, especially in migrant workers, ignoring the fact that these migrant workers were employed in concentrations of heavy or hazardous jobs. Ignorance, or carelessness denies the fundamental differences between employers and workers and supports a paternalistic managerial approach which contributes to the creation of a culture of masculinity and which regards concern for safety as a feminine trait. This view attributes minor accidents as deliberately caused by the worker to avoid work and has, in turn, caused employers and insurance companies to question the validity of worker compensation claims. (Quinlan 1998).

These notions have been confirmed in the literature, with the development and acceptance of terms such as "attitudinal pathos, compensation neurosis, bizarre hypochondrias, traumatic neurosis and malingering" Thus, the psychological literature which had been widely accepted as the authority upon which accident prevention methods could be developed, actually underpinned what Quinlan claims to be false notions attributing accident causation to individual behaviour.

Lamm et al (2008) emphasise the need to include cultural diversity and communication into any study involving workplace health and safety. Health and Safety practices are influenced by individual behaviour towards health and safety, determined by individual culture, organisational culture, communication and personal attributes. Verifying the nexus between workplace culture, $\mathrm{OH}$ and productivity will require the analysis of applied management practice and its effect on health and safety for contingent and precarious labour in the Kuwait construction industry, with the emphasis on small construction firms.

In order to ensure that the aims and objectives of the study are achieved, a triangulated approach will therefore be used as it incorporates multiple sources of evidence converging on the same sets of findings. This is particularly important in case study research. (Yin 1993;
Neuman 1994). Incorporating multiple sources of statistical information will ensure that accident statistics are more reliable. Qualitative and quantitative methodologies will be used in order to combat the challenges of communication in the Kuwait construction industry. This will ensure the reliability and validity of data and provide a holistic understanding of the problems in the Kuwait construction industry. A sample of 10 small construction firms and 4 large construction firms will be investigated, representing a cross-section of business traits, ethnicity, contractual and residential status against which specific problems relating to contingent workers in precarious employment can be effectively analysed.

A targeted approach will be adopted, as opposed to a random approach, in order to obtain the maximum amount of information about specific types of cases and management techniques. Using survey questionnaires for data collection is not advised as response rates are normally low. Correct interpretation of questions is crucial, and it will be essential to ensure that respondents understand the questions being asked. For this reason interviews will be conducted with managers, engineers, safety specialists and labourers in large and small firms. These interviews will be audiotaped and translated by sworn translators. Statistical information will be gathered from accident files of the safety departments at Kuwait Municipality and the Ministry of Social Affairs and Labour.

In order to more closely represent true statistics of accidents and morbidity rates and establish psychological and sociological connections with injury and accident causation, statistics will, in addition, be obtained from various private hospitals in Kuwait as well as, Human Rights agencies through various embassies who are closely involved with worker rights. The statistical information gathered during the interview process will provide valuable quantitative and qualitative data to enable to comparison of actual accident causation factors, incidents and death rates with those which are officially reported.

As the research topic involves gathering sensitive information, ethical approval will be sought and all appropriate procedures and methods used in order to retain confidentiality and protect both respondents and the researcher. This is a particularly difficult and challenging task, as great care needs to be taken not to offend cultural protocols whilst at the same time, gathering relevant and genuine data and ensuring confidentiality. For example, it is considered totally inappropriate for a woman to approach any man without being accompanied by a relative or approved person. For this reason, interviews will need to be arranged through site managers and held in site offices under the protection and in the company of a suitably qualified male figure, who will be a sworn translator. The interviews will be transcribed and interpreted by certified 
interpreters or persons approved by the United Nations, Human Rights or the Australian or US Embassy.

The safety of the researcher needs to be also taken into consideration. Gaining access to workers on site for the larger contracting companies will be concluded according to strict protocols as set by Kuwait Oil Company regulations and which are based on international HSE standards. Once protocols have been observed and permission gained from the HSE Project Managers and Engineers, the researcher will interview workers in site offices and not be exposed to any dangers on the oil fields themselves. Any person who has gained approval for entrance into these areas must by law be accompanied by the Site Engineer and another male, in order to ensure the safety of that person.

The managers of 10 smaller firms will be approached for interviewing. Where non-English speaking firms are involved, the researcher will ensure that only firms which operate within the immediate area of the city will be interviewed, thus not exposing herself to travelling long distances into the desert. The researcher will at all times observe the Muslim social protocol in terms of male accompaniment. When the researcher conducts a field visit, the researcher will be accompanied by a legal expert who is a sworn translator, as well as the researcher's husband. All people involved in the interview process and transcription will sign affidavits ensuring retention of confidentiality. Being accompanied by males when out of the home observes the strict Muslim code of social behaviour for females, which states that all women who appear in public should be accompanied by a male relative.

\section{Key Research Questions}

Given the scarcity of research in terms of the use of a multidimensional approach involving psychological, sociological, legal, cultural and managerial approaches affecting injury causation for contingent and precariously employed labour in the construction industry in Kuwait, key questions for the research are:

1. To what extent are injury causation and fatality rates for contingent and precarious workers in the Kuwait construction industry related to psychological, sociological, cultural and management practice in Kuwait?

2. How, and to what extent, does the complex nature of legislative structures and their application affect safety compliance, enforcement, accident and fatality rates for contingent and precarious labour in the Kuwait construction industry?

3. What are the key OHS issues for consideration by national and international agencies, such as Department of Labour, WHO and ILO as well as members of the Kuwait construction industry, such as site and project managers?
4. What recommendations can be made to improve the health and safety of contingent workers, precariously employed in the Kuwait Construction Industry?

\section{Conclusion}

Changes to employment patterns leading to the development of contingent labour precariously employed, particularly in the construction industry, has led to a growing demand that factors affecting accident causation and prevention in the construction industry are urgently addressed due to the positive relationship between the growth of contingent labour and a dramatic increase in workplace injury in small construction firms.

This situation is particularly relevant to the Kuwait construction industry, which has one of the highest accident rates in the world and employs the highest percentage of expatriate labour in the world.

Due to the complex nature of factors affecting the way in which Kuwaiti workers in the construction industry are managed, the research will adopt a multidimensional, targeted approach incorporating psychological, sociological, legal, cultural and managerial factors affecting the health and safety for contingent workers in the Kuwait construction industry.

The results of the study will inform the development of recommendations to Human Rights and Occupational Health and Safety agencies, International labour organisations, construction site and project managers in Kuwait. These recommendations, if adopted, will improve the rights, working conditions and health and safety of contingent labour in the region.

\section{References}

Abdel-Hadim, A and Al-Tuhaih (1989). In search of a new form of management: the case of the joint sector in Kuwait. Inerational Studies of Management and Organization. 19(2). 38-57.

Goudswaard A, Kraan, $\mathrm{K}$ and Verbruggen, V. (1999). Flexible Employment Policies and Working Conditions: European Bibliographical Review. TNO Work and Employment. April.

Human Rights Watch. (1993). Letter to His Highness
Sheikh Jaber al Ahmad Al Sabah, Amir of the
State of Kuwait.
www.hrw.org/press/2003/04/gccuwait.htm.

Human Rights Alert Series (2008). ALKWT 91.00. www.uscis.gov/files/nativedocuments/alkwt92001.pdf.. 
Interational Labour Office. (2001). Overview of the Thirteenth Asian Regional Meeting. www.ilo.org/public/english/region/asro/bangko $\mathrm{k} / \mathrm{arm} / \mathrm{kwt}$.htm.

Kartam, N. A. and Bouz, R. G. (1998) Fatalities and Injuries in the Kuwait Construction Industry. Accident Analysis and Prevision. 30(6) 805814.

Kartam, N. A., Flood, I, and Koushki, P. (2000). Construction safety in Kuwait: issues, procedures, problems and recommendations. Safety Science. 36. 163-184.

Kazemi, A. A. and Ali, A. J. (2001). Managerial problems in Kuwait. Journal of Management Development. 21(5). 366-375.

Letourneux. (1999). The working conditions of the Self-Employed in the European Union. Dublin. European Foundation, 13/9/1999.

Lingard, H. and Holmes, N. (2001). Understandings of occupational health and safety risk control in small business construction forms: Barriers to implementing technological controls. Construction Management and Economics. 19. 217-226

Loew, H. (2000). Analysis of the Kuwati Culture. www.everyculture.com/Ja-Ma/Kuwait.html

Longva, A. N. (1993). Kuwaiti Women at a Crossroads: Privileged Development and the Constraints of Ethnic Stratification. International Journal of Middle East Studies. 25(3). 443-456.

McVittie, D., Banikin, and Brocklebank, W. (1997) The effects of Firm Size on injury frequency in construction. Safety Science 27(1). 19-23.

Metle, M. K. (2002) The Influence of traditional culture on attitudes towards work among Kuwaiti women employees in the public sector. Women in Management Review. 17(6). 245261.

Nosar, I., Johnstone, R. and Quinlan, M. (2004) Regulating supply chains to Address the Occupational Health and Safety Problems Associated with Precarious Employment: The Case of Home-Based Clothing Workers in Australia. Australian Journal of Labour Law. 2.

Quinlan, M. and Mayhew, C. (2001). Evidence versus ideology: lifting the blindfold on OHS in precarious employment. The University of $\mathrm{New}$ South Wales. Department of Industrial Relations. Papers. 138.
Shah, M. N., Al Qudsi, S. S., and Shah, M. (1991). Asian Women Workers in Kuwait. International Migration Review. 25(3). 464-486.

Standing, H. and Nicolini. (1997). Review of Workplace-Related Violence. Tavistock Institute, Health and Safety Executive report (HSE) 143.

Sust, A. (1971) Das Unfallgeschehen in Abhangigkeit von der Betriebsgosse. Sichere Arbeit. 1 .

Tabtabai, H. M. (2002) Analyzing Construction Site Accidents in Kuwait. Kuwait Journal of Science and Engineering. 29(2).

Toscano, G. and Windau, J. (1994). Fatal work injuries from the 1992 census. Monthly Labor Review. Oct 39-48.

Valcarel, A. L. (2004) Safety and health in construction work. Asian-Pacific Newsletter on Occupational Health and Safety. 11, 4-7.

Weeks, J. and McVittie, D. (1995). Controlling injury hazards in construction. Occupational Medicine: Construction Safety and Health. 10(2). 395-405

Xia, Z., Lu, G. and Liang, Y. (2004). Challenges and strategies of occupational health and safety in the construction industry in China. Asian-Pacific Newsletter on Occupational Health and Safety. 11. 8-9.

Yin, R. K. (1993) Case study research - Design and Methods. Applied Social Research Methods Series. 5.

Author
Cathy Robertson
Department of Occupational Health and Safety
Auckland University of Technology
Private Bag92006
Auckland 1142
Cathy.Robertson@xtra.co.nz
Felicity Lamm
Associate Professor
School of Business - Management
Auckland University of Technology
Private Bag92006
Auckland 1142
Felicity.Lamm@aut.ac.nz

